\title{
Nuestro Tiempo, su sociedad y la revista como producto cultural en los años 50 de la república burguesa cubana
}

\author{
Nuestro Tiempo, its society and the magazine as a cultural product \\ in the 50s of the Cuban bourgeois republic
}

\author{
Yudith Rojas Tamayo \\ Universidad de Western (Ontario, Canadá) \\ yrojasta@uwo.ca
}

Adrián Ludet Arévalo Salazar

Universidad de Holguín (Cuba)

aarevalo@uho.edu.cu

\section{Resumen}

Durante la República Burguesa en Cuba (1902-1959), cientos de intelectuales desplegaron su labor en prestigiosas publicaciones e instituciones culturales como Carteles, Social, Revista de Avance, Orígenes, Orto, Bohemia y Nuestro Tiempo. Este artículo se acerca a la Sociedad Cultural Nuestro Tiempo y su revista, como patrimonios culturales de la nación cubana. El objetivo es describir y analizar la función de la Sociedad y, a su vez, de la revista como producto cultural; teniendo en cuenta, además, la estructuración de ambas por secciones de Música, Teatro, Cine y Artes Plásticas. A través de los métodos de revisión bibliográfica y análisis de contenido de sus ediciones en la década del ' 50 , se realiza una aproximación a sus principales integrantes; inquietudes culturales; sistematicidad de publicaciones y orientación ideológica. Se concluye que, a pesar de las perentorias condiciones económicas y persecuciones políticas a que fueron sometidos sus miembros, lograron trascender y concebir su revista como producto cultural, con un marcado carácter de izquierda. Al triunfar la Revolución cubana legaron grandes intelectuales que se insertaron en diversos sectores y las bases para la fundación del Instituto Cubano de Arte e Industria Cinematográficos (ICAIC).

\section{Palabras Clave}

Sociedad Cultural Nuestro Tiempo; Revista Nuestro Tiempo; teatro, música; cine; artes plásticas.

\footnotetext{
Abstract

During the Bourgeois Republic in Cuba (1902-1959), hundreds of intellectuals displayed their work in prestigious publications and cultural institutions such as Carteles, Social, Revista de Avance, Orígenes, Orto, Bohemia and Nuestro Tiempo. This article approaches 
the Sociedad Cultural Nuestro Tiempo and its magazine, as cultural heritage of the Cuban nation. The objective is to describe and analyze the function of the Society and, in turn, of the magazine as a cultural product; also taking into account the structuring of both by sections of Music, Theater, Cinema and Plastic Arts. Through the methods of bibliographic review and content analysis of its editions in the 1950s, an approach to its main members is made; cultural concerns; systematic publication and ideological orientation. It is concluded that, despite the peremptory economic conditions and political persecutions to which its members were subjected, they managed to transcend and conceive of their magazine as a cultural product, with a marked left-wing character. When the Cuban Revolution triumphed they bequeathed great intellectuals who were inserted in various sectors and the bases for the foundation of the Cuban Institute of Cinematographic Art and Industry (ICAIC).

\section{Keywords}

Sociedad Cultural Nuestro Tiempo; Nuestro Tiempo Magazine; theatre; music; cinema; plastic arts.

\section{Sociedad Cultural Nuestro Tiempo, la izquierda cultural en acción}

Fue la etapa republicana, comprendida entre 1902 y 1959, un espacio ideal para la aparición de cientos de revistas y periódicos de elogiable calidad. Desde los inicios de este período en Cuba, tales publicaciones nacieron en medio de una nación que prometía "ser de todos y para el bien de todos"1. Estas palabras martianas fueron tomadas como referencia por los distintos gobiernos de turno, pero vieron la luz bajo el dominio imperialista, con el sabor de un país a medias.

Publicaciones impresas como la Revista de Avance $^{2}$, surgida al calor del grupo Minorista en 1927; la revista Orígenes $^{3}$, compuesta por noveles poetas agrupados alrededor de José Lezama Lima; y la revista Nuestro Tiempo, nacida de la Sociedad Cultural de igual nombre, por ejemplo, fueron claros exponentes del accionar de talentosos e inquietos jóvenes ante la situación política que atravesaba el país.

Este artículo se acerca, en primer lugar, a la labor desarrollada por la Sociedad Cultural Nuestro Tiempo y, en segunda instancia, a su revista, como producto cultural. Atendiendo a las posturas asumidas por sus miembros y su repercusión social en la etapa republicana, son aún pocos los acercamientos que investigadores cubanos y foráneos han brindado a esta publicación de izquierda y de vanguardia. En la búsqueda de textos alusivos, tanto a la Sociedad Cultural, como a la revista, se encontraron, entre otros, el trabajo de diploma La Sociedad Cultural Nuestro Tiempo (1983), de Mayra Cardoso Madariaga y Tania Parson Peñaranda, perteneciente a la

\footnotetext{
${ }^{1}$ Frase expresada por José Martí, el Apóstol, durante un discurso en el Liceo Cubano, en Tampa, Estados Unidos, el 26 de noviembre de 1891

${ }^{2}$ Revista de Avance. Principal órgano del movimiento vanguardista cubano. De referencia obligada para estudiar el desarrollo de las artes en Cuba durante la época republicana. (1927-1930).

${ }^{3}$ Grupo y Revista Orígenes, 1944. Agrupación de intelectuales en la cultura cubana que se distinguió por la extraordinaria riqueza de sus aportes y la diversidad de estilos dentro del formidable conjunto de ideas y búsquedas que le dan unidad.
} 


\section{Nuestro Tiempo, su sociedad y la revista como producto cultural en los años 50 de la república burguesa cubana}

Facultad de Artes y Letras de la Universidad de La Habana; Revista Nuestro Tiempo. Compilación de trabajos publicados (1989); Sociedad Cultural Nuestro Tiempo. Resistencia y acción (2002), ambos del mismo autor, Ricardo Luis Hernández Otero; así como cerca de 10 artículos digitales, entre los que se hallan Nuestro Tiempo para el actual municipio Plaza de la Revolución, publicado el 18 de marzo de 2009 por Avelino V. Couceiro en el sitio CUBARTE; Sociedad Cultural Nuestro Tiempo, publicado el 26 de junio de 2009, en el sitio Laberintos; La Sociedad Cultural Nuestro Tiempo, publicado el 18 de junio de 2013 por Ramón Guerra, en el blog Cultura Cuba y la página web Tres entrevistas en torno a Nuestro Tiempo, publicada por María del Carmen Mestas y tomada de Romances, 8/73, pp. 12-14. Recientemente, se encontró el trabajo de diploma, La Sociedad Cultural Nuestro Tempo. Impronta de una cruzada por la cultura cubana (1951-1961), escrito en 2019 por César Noel Martínez Hernández.

El estudio de estas aproximaciones permitió conocer algunos detalles descriptivos que comprenden los anales, surgimiento y fundación de la Sociedad y la revista respectivamente; estructuración de ambas por secciones de Música, Teatro, Cine y Artes Plásticas; sus principales integrantes; inquietudes culturales y la sistematicidad de publicaciones, a pesar de las difíciles condiciones económicas a las que se enfrentaban sus integrantes y la persecución a que eran sometidos. Sin embargo, en ninguna de ellas se recoge un análisis del papel desempeñado por estos intelectuales en la defensa de la cultura nacional, ni el impacto que su revista tuviera como uno de los productos culturales más acabados en su intensa actividad.

En el aula número 8 del Conservatorio Municipal de La Habana, Cuba, se fundó en enero de 1951, la Sociedad Cultural Nuestro Tiempo. Con su Presidente, el destacado músico Harold Gramatges ${ }^{4}$ y Juan Blanco ${ }^{5}$ como Secretario quedó conformada su directiva, con la presencia, además, de Nilo Rodríguez, Edgardo Martín, Argeliers León, Manuel Duchesne Cuzán, entre otros intelectuales y artistas cubanos.

Orientada por el Partido Socialista Popular 6 , la Sociedad Cultural tuvo como objetivo nuclear a los intelectuales y artistas de izquierda, para estudiar las raíces de la cultura cubana y el aprendizaje de la filosofía marxista, en una sociedad que, según sus preceptos, debía estar compuesta por intelectuales progresistas, aunados en la renovación del ambiente cultural en Cuba.

Aun así, sus integrantes se enfrentaron a una dura realidad social. Fulgencio Batista, militar y político cubano, quien había sido Presidente de la República de Cuba durante el período de 1940-1944, tomaría el poder por segunda vez, a través de un

\footnotetext{
${ }^{4}$ Harold Gramatges Leyte-Vidal (1918-2008). Director de orquesta, compositor, pianista y profesor. Considerado uno de los más importantes representantes de la creación musical cubana del siglo XX. Su labor pedagógica ha representado un invaluable aporte a la enseñanza musical de Cuba.

5 Juan Pedro Blanco Rodríguez (1919-2008). Destacado compositor de vanguardia. Pionero de la Música Electroacústica en Cuba. Realizó más de 200 trabajos que incluyen música para coros, música electroacústica y por computadoras en todas sus modalidades, espectáculos de multimedia y diferentes ciclos de obras que comprenden música para la danza, el teatro, el cine y la gimnástica.

6 Partido Socialista Popular (PSP). Partido político cubano. Sucesor del primer Partido Comunista de Cuba, el cual existió en la ilegalidad entre 1925 y 1935.
} 
golpe de estado, el 10 de marzo de 1952. Como uno de los títeres del gobierno estadounidense que se sucedieron en la República Burguesa, no estaba interesado en encontrar soluciones ni acuerdos en el plano cultural. No obstante, recoge en uno de sus ensayos, la escritora, Graziella Pogolotti $(2010)^{7}$ que, años antes, gracias a la iniciativa de otro intelectual prestigioso, Raúl Roa, se diseñó un verdadero programa cultural coherente, bajo la presidencia de Carlos Prío Socarrás ${ }^{8}$ y refiere:

"Por una parte fortaleció el diálogo entre tradición y modernidad. Incorporó en sus publicaciones el rescate de textos significativos del siglo $\mathrm{XX}$, tales como las obras de Pablo de la Torriente Brau y, en lo referente a las artes plásticas, legitimó la vanguardia y la abrió a lecturas renovadoras que superaban el anquilosado debate con la academia. Mientras José Lezama Lima, todavía no consagrado por el establishment cultural, acercaba su poética a la de Arístides Fernández. Fernando Ortiz recorría, con visión antropológica, la obra de Wifredo Lam. El estímulo a la creación derribaba los límites de una filantropía paternalista mediante el fortalecimiento de los canales de comunicación con la sociedad".

En medio de esta situación política y con tales antecedentes culturales nació la Sociedad, con amplias inquietudes y necesidades de cambio. La inestabilidad e incertidumbre en el escenario intelectual motivaron a sus integrantes a nuclearse en torno a una idea: la resistencia desde la cubanidad más autóctona. Según recoge la Editorial Electrónica Cubaliteraria ${ }^{9}$, Portal del Instituto Cubano del Libro, no fue hasta el 10 de marzo de 1951, la inauguración oficial de la Sociedad. La actividad fue múltiple: apertura de la Galería de Artes Plásticas con la exposición "Veinte pintores y ocho escultores cubanos"; ejecución de un programa musical con canciones cubanas contemporáneas para coro mixto, bajo la dirección de Edmundo López; y la puesta en escena de la obra teatral "La más fuerte", del dramaturgo sueco August Strindberg, dirigida por Francisco Morín.

En una entrevista concedida a María del Carmen Mestas (2016), Harold Gramatges rememoró los inicios de este ambicioso y necesario proyecto que enfrentó amenazas y agresiones por parte del gobierno, en el camino de lograr sus objetivos.

"Así que, en sus comienzos, surge por la necesidad de dar impulso a una cultura
de raíz nacional, anulando mezquinas y artificiales diferencias entre distintos
sectores artísticos y culturales de ese momento, llevando a cabo la vinculación
de nuestro pueblo con sus artistas. En aquella primera etapa nuestra consigna
fue la de interesar al pueblo frente a toda creación artística. Para esto nos
propusimos un trabajo creativo constante, con el fin de darle vía a las
inquietudes que cada vocación lleva en sí, de manera que éstas se canalizaran

\footnotetext{
${ }^{7}$ Graziella Pogolotti Jacobson. Crítica de arte, prestigiosa ensayista y destacada intelectual cubana, promotora de las Artes Plásticas Cubanas. Presidenta del Consejo Asesor del Ministro de Cultura, Vicepresidenta de la Unión de Escritores y Artistas de Cuba. Miembro de la Academia Cubana de la Lengua.

${ }^{8}$ Carlos Prío Socarrás (1903-1977). Político cubano, presidente de la República entre 1948 y 1952.

${ }^{9}$ Disponible en: http://www.cubaliteraria.cu/monografia/sociedad nuestro tiempo/Consultado el 11 de noviembre de 2019
} 


\title{
Nuestro Tiempo, su sociedad y la revista como producto cultural en los años 50 de la república burguesa cubana
}

produciendo obras de valor permanente, enriqueciendo la producción nacional en los distintos aspectos del arte y la cultura".

Este criterio de Gramatges sintetiza una de las más nobles intenciones de este grupo de intelectuales preocupados por el destino de la nación cubana. Luego de cuatro décadas de gobiernos de turno manipulados por los intereses norteamericanos y proyectos nacionales frustrados como Avance y Orígenes, la Sociedad retomó los pilares de la necesaria autonomía cubana y se declaró fiel continuadora de quienes le antecedieron. Sin darse por vencidos, sus integrantes se erigieron como un frente de resistencia y acción, en circunstancias donde aún se creía en el poder transformador de la cultura como generadora de cambios sin violencia.

Inquietos ante la tarea propuesta, sus integrantes crearon lo que sería el primer número y único de esa primera etapa, de la revista Nuestro Tiempo. Consolidada luego, como el vehículo ideal para comunicar sus postulados, en su primera entrega se incluyó un "Manifiesto", que recoge los lineamientos básicos del trabajo cultural de la Sociedad y sus proyecciones éticas y estéticas. Firmado por 30 intelectuales y escritores de la época, entre los que destacan Rafaela Chacón Nardi, Carilda Oliver Labra, Harold Gramatges, Roberto Fernández Retamar, Guillermo Cabrera Infante y Tomas Gutiérrez Alea, el Manifiesto expuso:

\begin{abstract}
"Surgimos para traer el pueblo al arte, acercándolo a las inquietudes estéticas y culturales de nuestro tiempo, precisamente ahora en que, intuyendo ya estas realidades, demanda un vehículo que le permita palparlas y asimilarlas para su más rápida formación y madurez cultural. Para desarrollar esta labor, mantendremos un centro de arte y cultura permanente, que ofrecerá teatro, música, cine, ballet, exposiciones de artes plásticas, conferencias, y editará las manifestaciones literarias, poéticas y filosóficas que produzca nuestra generación". (Gramatges,1951)
\end{abstract}

Ante estas afirmaciones de sus miembros era necesario el surgimiento de la Sociedad, en una década convulsa, como lo fue 1950. Si tenemos en cuenta los anteriores proyectos culturales, como los propuestos desde los grupos Minorista y de Orígenes, por ejemplo, estos no habían cumplido el sueño añorado de instaurar una sociedad justa por medio de los valores culturales, criterio que defienden además varios investigadores, como Graziella Pogolotti.

En este sentido, los intelectuales se replanteaban el rescate de un proyecto nacional, lastrado por la intervención imperialista. Superaban el callejón sin salida planteado por Jorge Mañach ${ }^{10}$ en La crisis de la alta cultura en Cuba (1925), donde se expresa que la nación surgida en 1902 en Cuba es una nación sin soberanía, en la cual se ha perdido la alta cultura y el ideal nacional. Para recuperarlo se imponía la restauración de la alta cultura y, por tanto, se debían hacer dos cosas importantes: estimular a los sectores intelectuales - protagonistas del rescate- y transmitir esa cultura al pueblo. De esta forma, la cultura se convertía en el único camino para

${ }^{10}$ Jorge Mañach Robato (1898-1961). Eminente intelectual y político cubano. Doctor en Filosofía y Letras y notabilísimo escritor y periodista. 


\section{Yudith Rojas Tamayo y Adrián Ludet Arévalo Salazar}

alcanzar la libertad, en una República que atravesaba momentos de crisis. En este proceso de concientización y análisis, alentados por los estudios de Fernando Ortiz, antropólogo, jurista, arqueólogo y periodista cubano, los miembros de la Sociedad descubrían también el alcance de las raíces afrocubanas. Para el contexto caribeño, resultaba el equivalente de la reivindicación indigenista de los mexicanos.

En 1953 se intensificó la actividad del Partido Socialista Popular (PSP) en la Sociedad Cultural Nuestro Tiempo, lo que hace que la misma se convierta en uno de los frentes más importantes de la Comisión para el Trabajo Intelectual (1953), que se crea dentro de la Sociedad y que fue integrada por Carlos Rafael Rodríguez, Juan Marinello y Mirta Aguirre. Esta última asume la responsabilidad de atenderla directamente.

Es en esta etapa, donde se fundaron diferentes secciones con un carácter independiente y autónomo en el orden artístico, lo que garantizaba la sistematicidad y diversificación de las actividades culturales. Esta estructura sería la columna vertebral de sus acciones y así lo plasmarían, posteriormente, en la revista Nuestro Tiempo.

La Sección de Cine-debate fue la primera fundada y dirigida en diferentes períodos por José Massip, Julio García Espinosa y Alfredo Guevara. Comenzaron a publicarse boletines de cine que constituyen los antecedentes de las publicaciones posteriores de la Sociedad, como los "Cuadernos de Cultura Cinematográfica".

Como parte de las actividades de esta Sección se organizaron numerosos ciclos de cine-debate, de aquellas filmografías de escasa presencia en el país, es decir, cine sueco, japonés, alemán, italiano, inglés, francés; ciclos de clásicos del cine, así como conferencias, talleres de actuación y dirección y cursos de apreciación de los aspectos técnicos de este arte. En este sentido, intensifica su labor en la búsqueda de una cinematografía nacional que contrarrestara la inundación del mercado nacional con producciones mediocres provenientes de Estados Unidos, México, Argentina y España, con especial interés en la divulgación de las experiencias, logros y dificultades de otras cinematografías foráneas como la italiana, la brasileña, la francesa, la inglesa, entre otras.

Luego, se funda la Sección de Música, cuya directiva quedó integrada por Manuel Duchesne Cuzán, María Antonieta Henríquez, Argeliers León, Edgardo Martín, Serafín Pro y Nilo Rodríguez. Dentro de sus propósitos, comenzaron un proceso de divulgación de la música culta, clásica y contemporánea cubana. Para ello, entre otras muchas acciones, rescataron los aportes de músicos como Amadeo Roldán y Alejandro García Caturla, muy desvalorizados para esa época y envueltos en escándalos familiares. Promovieron la necesidad de la creación nacional frente a la penetración norteamericana, a través de la organización de numerosas audiciones y conciertos de artistas foráneos y nacionales, de jóvenes creadores como Carlos Fariñas, Leo Brouwer y otros. (Otero, 2002)

Un año más tarde, 1954, fue el momento propicio para fundar la Sección de Artes Plásticas por Marta Arjona y Eugenio Rodríguez. El 21 de diciembre, coincidiendo con la apertura de la nueva sede de Nuestro Tiempo en el Vedado, tuvo lugar la 


\section{Nuestro Tiempo, su sociedad y la revista como producto cultural en los años 50 de la república burguesa cubana}

inauguración de la Galería Permanente de Artes Plásticas. En sus salones se dio cabida a lo más representativo de la plástica cubana moderna de las más diversas tendencias y presupuestos estéticos. (Otero, 2002)

Se llevaron a cabo exposiciones colectivas e individuales, tanto de los grandes maestros del movimiento moderno cubano como Víctor Manuel, Amelia Peláez, Carlos Enríquez y otros, como de jóvenes creadores, Raúl Martínez y René Ávila. Al mismo tiempo del montaje de exposiciones, la Sección organizó numerosas conferencias, cursos sobre artes plásticas, proyección de documentales de arte, entre otras actividades.

De particular importancia fue la labor política desplegada por esta Sección con el fin de promover entre los artistas plásticos del país, el rechazo a la II Bienal Hispanoamericana de Arte patrocinada por el franquismo. Como contrapartida numerosos artistas expusieron sus obras en lo que popularmente se denominó la "Anti-Bienal", la cual se inauguró en los salones del Lyceum Lawn Tennis Club. El éxito alcanzado por la "Anti-Bienal" fue un elemento catalizador que contribuyó a la organización de la Sección a fines de 1954. (Saínz \& Hernández, 2003)

La Sección de Teatro se organiza igualmente a fines de 1954 por Nora Badías y Vicente Revuelta. Los objetivos de esta Sección se dieron a conocer en el "Primer Cuaderno de Cultura Teatral”, publicado en enero de 1955. Esta Sección realizó actividades encaminadas al conocimiento y debate del teatro cubano y universal a través de la puesta en escena de importantes obras teatrales, de intercambios entre público y teatristas sobre los problemas de la escena nacional, de lectura por parte de los autores de piezas aún inéditas, así como de la crítica desde las páginas de la revista Nuestro Tiempo al estado de esta manifestación artística en Cuba.

En otras declaraciones a María del Carmen Mestas (2016), en entrevista realizada a Harold Gramatges, este destacó que:

"El primer trabajo de carácter colectivo fue la creación del Teatro Guiñol en Cuba. Pintores, actores, músicos, escultores, escenógrafos, atinaron sus esfuerzos con ese objeto. Entre las obras que se montaron bajo la dirección de Dulce María Farías recuerdo: "Sonatina", de Rubén Darío; "No hay que perder la cabeza", adaptación de Paco Alfonso; "La Obstinación de las Mujeres", farsa francesa anónima; "Los Títeres son Personas", de Nicolás Guillén, y otras que escapan a la memoria".

Sobre estas secciones y su trabajo en el período, vuelve la ensayista Graziella Pogolotti (2010) en sus introspecciones, donde recuerda que:

"El Patronato del Teatro garantizó la continuidad de estrenos dramáticos y respaldó el trabajo de actores y directores siguiendo una línea estética que no transgredía las convenciones establecidas. Original organización femenina, el Lyceum y Lawn Tenis Club consolidó un programa más integral. Difundió mediante charlas de reconocidos intelectuales cubanos y de otros países las tendencias contemporáneas del pensamiento y la literatura. Su galería fue el ámbito destinado al reconocimiento de los artistas de vanguardia. Ofreció su sala a la zona experimental de la música. Mantuvo una biblioteca pública 
circulante. La Hispano-cubana de cultura se debió, básicamente, a la voluntad aglutinadora de Fernando Ortiz".

Estas iniciativas no fueron más que la concreción de los anhelos de un grupo de intelectuales y escritores, que confiaban en el carácter transformador de la cultura en sus más disímiles expresiones, en la búsqueda de ese camino tan aclamado y necesario como la libertad. Tales objetivos quedaron muy claros en el Manifiesto publicado en 1951 y a los cuales fueron fieles, pues:

"El afán creador implícito en el hombre, al tomar en nuestro medio la suficiente fuerza de presencia, ha motivado que concentremos nuestros esfuerzos para hacer realidad lo que como nueva generación cubana creemos deber histórico: la preservación de los valores logrados y la divulgación de aquellos que apuntan su importancia vital. Nuestra estética es la de un arte americano, libre de prejuicios políticos o religiosos, enaltecido por encima de concesiones, que sea síntesis de lo que estimamos vigente y permanente en América. No nos interesan ni la oscuridad muerta ni la endeblez académica, sino una estética tan infinita como el hombre mismo“. (Gramatges,1951)

Como continuadora del legado de Avance y Orígenes, esta Sociedad selló su compromiso con la cultura cubana. Una voz que se había visto amenazada por el golpe de Batista en 1952, muestra de los ataques a la soberanía nacional y por ello, la Sociedad tomó otra dimensión política. A través de sus actividades en las diferentes secciones fue orientando la cultura en un sentido antimperialista, con la finalidad de impedir la penetración y el colonialismo cultural, que en esos momentos se intensificaba.

Tal actitud tuvo sus consecuencias. En una de las anécdotas que Gramatges compartió en sus declaraciones a María del Carmen Mestas, comenta que fue invitado por Mr. Jacob Canter, agregado cultural de la Embajada de Estados Unidos en Cuba, a una entrevista. Allí se le comunicó que había sido seleccionado para disfrutar de una beca Guggenheim ${ }^{11}$, de composición musical, pero para obtenerla, debía renunciar a la presidencia de Nuestro Tiempo, así como tratar de disolver la institución: Esta oferta para mí resultaba un chantaje, ya que yo no había solicitado dicha beca. Ya imagina usted cómo le respondí al yanqui. A esto llegaba el cinismo con que ese señor trataba a los intelectuales cubanos. (Mestas, 2016)

En medio de la compleja situación política y erigida públicamente como frente de acción ante el gobierno batistiano, la Sociedad no cedió espacio a las amenazas, cortes de fluido eléctrico, registros a sus instalaciones o censuras. A pesar de las vicisitudes y aprovechando las ventajas que le concedían su ubicación en la capital cubana, Nuestro Tiempo desplegó una intensa labor de rescate y consagración de lo más autóctono del criollismo cubano. Brindó arte en todas sus manifestaciones y para todos los niveles culturales, en una Cuba que sufría de una alta tasa de

11 Beca Guggenheim. Creada en 1925, es un subsidio otorgado por la John Simon Guggenheim Memorial Foundation a profesionales avanzados en todos los campos del saber, salvo en las artes escénicas. 


\section{Nuestro Tiempo, su sociedad y la revista como producto cultural en los años 50 de la república burguesa cubana}

analfabetismo y frustración. Es por ello que la masificación y defensa de la cultura nacional cubana en esa convulsa década de los '50 estuvo a cargo no solo de las actividades que la Sociedad realizó en sus sedes, sino a través de la revista que crearon como órgano oficial de sus postulados. Una publicación que por la sistematicidad e impacto de sus contenidos trascendió la cotidianidad de la sociedad cubana en otro intento de concientización de la necesaria libertad del país. Tales propósitos permitieron que a la luz de nuestros días esta publicación sea valorada en este artículo como un producto cultural de invaluable importancia.

\section{Revista Nuestro Tiempo como producto cultural de la Sociedad}

Precisamente fue la revista Nuestro Tiempo, uno de los más acabados productos culturales de la Sociedad, como canal formal de difusión de sus posiciones ideológicas en el ámbito de la cultura. Desde sus páginas se hacía crítica y reseña de la cultura nacional, asumiendo una posición de defensa de nuestras raíces, del arte y de la literatura en el país.

Fundada en abril de 1954, Nuestro Tiempo, de carácter bimensual, constituyó el órgano oficial de la Sociedad hasta 1960. Esta publicación tenía una tirada de entre mil y dos mil ejemplares y se distribuía gratuitamente a los socios, mientras que una pequeña parte se vendía al precio de 20 centavos. La dirección de la revista estuvo a cargo de Harold Gramatges y administrada por Juan Blanco. Su comisión editora la integraron, regularmente, Rafaela Chacón Nardi, Fornarina Fornaris, Amado Palenque, José Massip, Nilo Rodríguez, Ithiel León, entre otros.

Entre los ilustradores de la revista podemos mencionar al pintor vanguardista cubano Wifredo Lam, quien estuvo a cargo de la portada del número inicial de la revista. Asimismo, desde mayo de 1955 se publicaron poemas y cuentos de prestigiosos escritores nacionales como Nicolás Guillén, Onelio Jorge Cardoso, Manuel Navarro Luna, Regino Pedroso, Labrador Ruiz, junto a jóvenes creadores como Pablo Armando Fernández, Raúl Aparicio, Rosario Antuña y Adolfo Martí.

La revista incluía periódicamente trabajos especializados, reseñas y notas divulgativas sobre el acontecer cultural de la Sociedad y nacional; así como la sección Microcríticas, destinada exclusivamente al cine en 1954 y que posteriormente se amplió al teatro, a la música y más tarde, a las artes plásticas y a la literatura.

La revista fue uno de los mayores logros de la Sociedad. Si se tiene en cuenta que la misma se hizo eco de las principales actividades organizadas por la institución, donde confluían además el poder de la imagen en fotografía y artes plásticas, así como la defensa a ultranza de las tradiciones cubanas, se puede afirmar que la revista orientaba el tipo de consumo cultural que debía prevalecer en Cuba.

Para hacer efectivo este consumo es necesario apuntar que un producto cultural es creado por la industria cultural con contenidos simbólicos, y destinados finalmente a los mercados de consumo con una función de reproducción ideológico y social. De esta manera, los productos denominados culturales tienen valores de uso y de 
cambio, contribuyen a la reproducción de la sociedad y a veces a la expansión del capital, pero en ellos los valores simbólicos prevalecen sobre los utilitarios y mercantiles (García, 1993)

La Sociedad y su revista como parte de la maquinaria industrial, a pesar de sus intenciones, fueron parte de ese modelo de análisis con base en la producción, distribución y consumo existente en Cuba en la década del '50. No obstante, es admirable el empeño y la responsabilidad que este grupo de intelectuales sintió hacia su nación. Teniendo conciencia de su poder como voceros públicos, se apoyaron en la riqueza cultural cubana para hacer frente a todo el mercado internacional que se introducía en el país, a través de la música, el teatro, el cine y otras manifestaciones. Su esfuerzo por contrarrestar el sentimiento de que lo foráneo era mucho más estilizado y de mejor calidad que la producción nacional fue la batalla contante de Nuestro Tiempo en el terreno cultural.

Uno de los elementos identitarios cubanos, sin dudas, es el campesinado. Sus costumbres y tradiciones son orgullo para el patrimonio. Sin embargo, durante la República Burguesa fue el sector poblacional más afectado por sus niveles de pobreza, insalubridad, educación y derechos sobre la tierra. A ellos, Nuestro Tiempo dedicó espacio en sus páginas, para plasmar el valor de su idiosincrasia. Hizo estudio de su folclore, con especial interés en ese caudal musical maravilloso que brota espontáneamente del pueblo y cómo se perdió o modificó por agentes exteriores.

Para no olvidar la magia de sus cultivadores, la musicóloga y pedagoga cubana, María Teresa Linares, publicó un artículo en la revista luego de convocar una Mesa Redonda en la Sociedad Nuestro Tiempo, con la idea de poner al frente las opiniones más autorizadas en materias de música popular. De esa manera sus cultivadores opinaron sobre los valores positivos o negativos, de los aspectos de la música moderna comparándola con la anterior y, en especial, con la campesina. Este fue uno de los aspectos más destacables:

"La décima es la forma de texto más generalmente usada en el punto guajiro y tiene un común denominador en todos los pueblos de habla hispana en la América. Su localización en los pueblos que todavía lo usan es siempre rural. Son conocidas las payadas o trovadas de los gauchos argentinos, que también usan la décima como texto de varios géneros como cifras y medias cifras, trovadas, estilos, tonos y milongas en las formas siguientes: décima glosada, décima con estrambote o estribillo, décimas improvisadas a lo humano y a lo divino y el encadenado, que consiste en comenzar un cantor con el último verso de su contrincante". (Linares, 1954)

Como resultado se expuso que, lejos de estar en decadencia, sus cultivadores y su público fueron cada vez en aumento, sin que esto modificara o alterara su verdadera esencia. Este fue uno de los más loables empeños de la Sociedad, al jugar con un caudal cultural obviado hasta ese momento y trayéndolo al público en general, como algo que debía ser atesorado y disfrutado. Fue la oportunidad de poner en existencia otro arte diferente al mexicano, francés, americano, etc., que ya convivían en Cuba, pero reconociendo que no eran los únicos. Aquí se evidencia la capacidad ilimitada 


\section{Nuestro Tiempo, su sociedad y la revista como producto cultural en los años 50 de la república burguesa cubana}

que posee una publicación para manipular a las audiencias.

Destacable fue, además, la posición asumida por Nuestro Tiempo ante la organización en Cuba de la II Bienal Hispanoamericana. Este acto, programado para el 28 de enero de 1954, sería el encargado de clausurar de manera oficial el primer centenario del natalicio de José Martí. Como certamen de arte contemporáneo fue auspiciado por el régimen franquista y el gobierno batistiano. Diversas publicaciones se hicieron eco de este acontecimiento, como el Diario de la Marina, vocero principal de la burguesía, en especial de los comerciantes e intereses españoles en Cuba reservó varias de sus páginas para plasmar las impresiones de aquel acto.

"La celebración, en La Habana, de la Segunda Bienal Hispanoamericana de Arte constituye, sin duda alguna, el acontecimiento artístico más importante que haya tenido lugar jamás, en Cuba. Ningún evento mejor para la inauguración del nuevo Palacio de Bellas Artes, uno de los de mayor capacidad en el mundo, y ningún cierre más apropiado para las fiestas del Centenario de Martí, que este homenaje internacional, en el que se juntarán centenares de artistas hispanoamericanos de primerísima categoría”. (Martínez,1953)

Era de esperar que estas fueran las opiniones de sus periodistas, pues defendían la presencia española en Cuba. En este sentido no había motivos para opacar la trascendencia de la Bienal que traía al país lo más novedoso en el terreno de la cultura. Y, en cierto modo, a primera instancia, esta era la realidad, incluso valorada desde nuestros días.

"Para Cuba, en cambio, la II Bienal, al igual que la primera para España, marcó en su escena y desarrollo artístico contemporáneo un innegable hito, un antes y un después que -además de poner en escena el inicio de la atracción cubana de la mano del grupo Los Once ${ }^{12}$ y la cohesión entre los artistas para el rechazo de una iniciativa oficial- obligó a un replanteamiento de su política artística”. (Cabañas, 2013)

Sin embargo, una mirada más profunda a este suceso llevó a varios de los miembros de la Sociedad a reflexionar ante la presencia franquista en la Isla y su alianza con el gobierno de Batista, el cual había designado un alto presupuesto para la organización de la misma, cuando pudo haberse realizado desde el país sin injerencias. De esta manera, reconocidos artistas de la plástica cubana como Amelia Peláez, Mijares, René Portocarrero, Marcelo Pogolotti, Mario Carreño, Mariano Rodríguez y Jorge Arche dirigieron por escrito su desacuerdo a la Comisión del Centenario.

Primero: Que nos parece absurdo que uno de los festejos del Centenario de José

\footnotetext{
12 Grupo Los Once. En Cuba se conoce la influencia del movimiento abstracto norteamericano en los artistas nacionales. Entre las tendencias más destacadas se encuentran la abstracción informalista y los concretos. Las figuras más destacadas de esta corriente abstracta se unieron en el grupo Los Once, como se hicieron llamar por el número inicial de participantes, y en el de los Concretos.
} 
Martí sea la celebración en La Habana de la II Bienal Hispanoamericana, dado que dicha Exposición está estructurada con un país extranjero, por tratarse de una continuación de la I Bienal celebrada en Madrid, y convocada por el Gobierno español. (Augier, 1954)

Como alternativa, pidieron que se les dejara organizar una "Exposición Martiana Internacional de Arte", pero tuvieron que homenajear a Martí con sus propios medios al ser ignoradas sus peticiones. Así nació la "Exposición de la Plástica Cubana Contemporánea" en los salones del Lyceum y Lawn Tennis Club, con más de 80 obras representativas de las tendencias dominantes del arte cubano, firmados, entre otros, por Víctor Manuel, Marcelo Pogolotti, Jorge Arche, René Portocarrero y Amelia Peláez.

Asimismo, Nuestro Tiempo, como parte del grupo de artistas anti-bienales respalda la inauguración del "Primer Festival de Arte" el 17 de mayo de 1954, junto a la Federación Estudiantil Universitaria (FEU), en los salones de la Escuela de Derecho de la Universidad de La Habana. La muestra fue calificada como la invasión de la libertad. El maestro Harold Gramatges, sumado a este movimiento, ofreció también un concierto de música cubana. Estos fueron claros ejemplos de la posición y el protagonismo asumidos por los intelectuales y artistas cubanos en aquella etapa de invasión extranjera en el consumo cultural del país.

Con la estabilización de la revista a partir de 1955, se sistematiza la sección de crítica que adoptó el nombre de Balcón de Nuestro Tiempo. A partir de julio de 1956 la crítica artística se independizó por manifestaciones: Los Libros, El Cine, El Teatro, La Música, a cargo de Fornarina Fornaris, Amado Palenque, Argeliers León, Harold Gramatges, José Massip, Edgardo Martín, Julio García Espinosa, entre otros.

Se intensificó el perfil divulgativo y crítico de las diferentes Secciones. Se publican numerosos trabajos especializados que abordaban aspectos teóricos sobre el cine, música, artes plásticas, teatro; semblanzas y entrevistas a figuras sobresalientes; se tradujeron artículos de revistas como Cinema Nuevo, Cinéa-Cine, Cahiers du Cinema, y se llevó a cabo la denuncia a las condiciones, los intereses y prioridades de la industria cinematográfica cubana, entre otros asuntos de interés nacional.

Afirma Yolanda Aguirre, que también tenían una biblioteca que funcionaba en uno de los locales de 23 y 4, en La Habana. Allí trataban de no tener libros que pudieran ser "comprometedores", ya que frecuentemente la biblioteca era visitada por los agentes del Servicio de Inteligencia Militar ${ }^{13}$ y el Buró para la Represión de las Actividades Comunistas ${ }^{14}$, y si encontraban una novela de Dostoiewski, escritor ruso, podían considerarlo subversivo.

Fornarina Fornaris, profesora de la Universidad de La Habana, participante activa de la Sociedad, se acerca al papel que ejerció la Sociedad y la revista desde su génesis:

"Se pueden señalar dos etapas en la historia de la Sociedad: una primera etapa

\footnotetext{
${ }^{13}$ Servicio de Inteligencia Militar (SIM) Institución militar cubana creada en 1934 y disuelta en 1959.

${ }^{14}$ Buró para la Represión de las Actividades Comunistas (BRAC). Institución policial creada Fulgencio Batista luego de los sucesos ocurridos el 26 de julio de 1953 en Cuba.
} 


\section{Nuestro Tiempo, su sociedad y la revista como producto cultural en los años 50 de la república burguesa cubana}

precaria, inicial. Es la época en que funcionaba en los salones de la Artística Gallega, en La Habana Vieja, donde en algunas ocasiones hubo que dar conferencias a la luz de un quinqué. A partir de 1953, con motivo del giro político que significó el asalto al Cuartel Moncada, se va a iniciar la segunda etapa de la Sociedad. (...) Hojeando algunos números (...) se pueden leer artículos, entrevistas, reseñas de libros y críticas de cine, teatro y música, que vertebran una posición de defensa de nuestra cultura, y del arte y de la literaturas universales, progresistas y revolucionarios". (Mestas, 2016)

Alega, asimismo, Fornaris que la mujer jugó un papel fundamental en Nuestro Tiempo, pues en la directiva de la Sociedad estaban, entre otras: María Antonieta Henríquez, que atendía la sección de música; Marta Arjona, en artes plásticas; Wanda Aguirre, en la biblioteca; Nora Badía, en teatro; Geisha Borroto y otras en diferentes vocalías; así como escritoras, pintoras, artistas, etc., que colaboraban sistemáticamente.

Con una tradición en el ejercicio de pensamiento y la crítica, desde las páginas de Nuestro Tiempo, se privilegió la apertura a nuevos horizontes desde el arte, en medio de un contexto histórico hostil y violento.

"En este sentido, la Sociedad Cultural Nuestro Tiempo y su revista pueden estimarse un estadio superior en la organización de esa resistencia desde el terreno de la cultura, pero a la vez una manera distinta de asumir esa resistencia que se convierte, en quienes prohijaron el proyecto y lo llevaron a vías de realización, en acción militante, comprometida, a favor del cambio necesario que comenzó a fijarse poco tiempo después de su nacimiento, y al que la Sociedad, sus directrices y sus miembros aportarían más tarde la experiencia ganada durante el combate en circunstancias difíciles, adaptándola a las condiciones y necesidades de la nueva época histórica abierta en enero de 1959". (Saínz \& Hernández, 2003)

Durante su labor en favor de la cultura cubana, Nuestro Tiempo, mantuvo como constancia su definición por el hombre, que nunca está en crisis, como bien declararon en su Manifiesto en 1951, y por su obra, que es su esencia permanente. Para este, ubicado en el centro de su producción, se erigió el trabajo sistemático y constructivo, en el que se incentivó la inquietud y la sensibilidad por lo humano y justo.

Para Ricardo Luis Hernández Otero, en su acercamiento a la herencia cultural de valiosos grupos como el Minorismo en torno a la Revista de Avance, Orígenes y, por último, Nuestro Tiempo, estos hicieron suyas las revistas, como espacios públicos de debate. Por tanto, se pueden esbozar algunas luces de lo que representaron para el momento en que salieron a la luz pública.

. (...) sí puede considerarse que ellas clasifican, y no desde la perspectiva actual, entre las más logradas y representativas muestras en cada uno de esos momentos, y que las tres se van vinculando entre sí - coincidencias y discrepancias, aceptaciones y rechazos, tanto explícitos como implícitos mediante, en una línea de continuidad y convergencia que alcanza su más 
apropiado cauce integrador con el triunfo de la Revolución en 1959. Son, en conclusión, tres ejemplos paradigmáticos de nuestra evolución cultural en el siglo XX." (Saínz \& Hernández, 2003)

Al triunfar la Revolución, en enero de 1959, expresó Gramatges que la Sociedad Nuestro Tiempo, no tenía razón de ser. Sus miembros más destacados fueron asumiendo cargos dirigentes o desarrollando al máximo sus aptitudes creativas. Sin embargo, fue escenario de importantes conferencias, como la impartida por el Comandante Ernesto Che Guevara con el nombre Proyecciones Sociales del Ejército Rebelde; o la de Alfredo Guevara sobre La creación del Instituto Cubano del Arte e Industria Cinematográficos.

El 24 de marzo de 1959 se hizo pública la Ley No.169 del Consejo de Ministros del Gobierno Revolucionario de la República de Cuba, que crea el Instituto Cubano del Arte e Industria Cinematográficos (ICAIC), cuyo presidente fundador fue Alfredo Guevara, hasta su muerte en 2013. Como reconocimiento al trabajo de la Sociedad

Cultural, esta se convirtió en referente para organizar el ICAIC, especialmente en el área de cine. La ley No.169 en su artículo primero, definía la finalidad de la Institución de "organizar, establecer y desarrollar la Industria Cinematográfica, atendiendo a criterios artísticos enmarcados en la tradición cultural cubana, y en los fines de la Revolución...".

El marco de libertad creadora del ICAIC en los años sesenta, propició la formación y consolidación de cineastas y profesionales del cine. Nombres como el de Tomás Gutiérrez Alea (Titón), Humberto Solás, Santiago Álvarez y el Noticiero ICAIC Latinoamericano, entre otros, contribuyeron al prestigio que internacionalmente alcanzó el ICAIC desde los primeros años de fundado (Cantón \& Hurtado, 2006).

Estos logros fueron, en gran medida, gracias a la experiencia y profesionalidad que muchos de sus miembros habían obtenido tras su trabajo como parte de la Sociedad Cultural, en el empeño que los intelectuales pusieron en cuidar nuestra idiosincrasia, no dejarnos manipular, ni endulzar.

\section{A modo de conclusiones}

La revista Nuestro Tiempo formó parte de las publicaciones literarias que, en Cuba, ilustran una de las más firmes, sabias, renovadoras y audaces conductas de la intelectualidad cubana. Sus distintos números están impregnados de fuertes sentimientos y proyecciones nacionalistas, donde se destaca su vocación antimperialista, como fiel continuadora de los anteriores proyectos republicanos. Páginas llenas de música, cine, teatro y artes plásticas llegaron con carácter bimensual a la minoría del pueblo que ha aprendido a leer y a escribir, escritas con la rebeldía de voces que acusan a un gobierno que recrudece la cultura y privilegia la violencia. Editoriales, notas, obituarios, informaciones, comentarios, críticas, reportajes y crónicas se adueñan de la libertad de las palabras que provocan la persecución constante de sus redactores y la inminente amenaza del cierre de la 


\section{Nuestro Tiempo, su sociedad y la revista como producto cultural en los años 50 de la república burguesa cubana}

institución.

El cuestionamiento de la realidad, la crítica a las decisiones gubernamentales que lesionaban la integridad de la Cultura nacional, así como la toma de partido ética y estética en relación con aspectos medulares de la vida intelectual cubana, se dieron a conocer en los numerosos editoriales que publicó la revista desde su fundación. Los principales objetivos de la revista fueron la divulgación y evaluación sistemática del acontecer cultural del momento, a través de sus críticas, reseñas y notas informativas; la defensa de los más auténticos valores de la cultura cubana frente a la avalancha mediática norteamericana, así como el enfrentamiento directo a la política del Instituto Nacional de Cultura, lo que se llevó a cabo por medio de los enérgicos editoriales y los artículos especializados.

Las valoraciones que hoy se encuentran del accionar e historia de la Sociedad y la revista Nuestro Tiempo han permitido una nueva mirada a su legado en la actualidad. Su función como producto cultural en la década del '50 en Cuba, se demuestra por su constante lucha en orientar el tipo de consumo cultural que debía existir en el país, privilegiando el mercado nacional. La cultura cubana fue un baluarte que defendieron sus intelectuales como elemento de soberanía y derecho de disfrute con orgullo por todos los ciudadanos. Es meritorio reconocer que Nuestro Tiempo fue un frente de resistencia contra la penetración cultural extranjera en Cuba, así como fuente de referentes culturales para la Revolución cubana.

\section{Bibliografía}

Augier, Á. (1987). Prólogo. En C. R. Rodríguez, Letra con filo. Ciudad de La Habana: Ediciones Unión.

Augier, Á. (1954). La Exposición de Plástica Cubana en homenaje a José Martí. Bohemia (6)

Austin, T. (1995). La página del profe. Recuperado el 23 de diciembre de 2009, de La página del profe: www.lapaginadelprofe.cl

Barei, S. (1999). Periodismo cultural: crítica y escritura. Revista Latina de Comunicación Social, No.23. Recuperado el 7 de noviembre de 2013, de Revista Latina de Comunicación Social, No.23: http://www.ull.es/publicaciones/latina/a1999bno/15silvia.htm

Basail, R., \& Álvarez, D. (2004): Sociología de la cultura. Lecciones y lecturas. Centro Cultural Juan Marinello, 2004.

Bourdieu, P. (1990): Sociología y Cultura. Buenos Aires: Editorial Grijalbo, S. A. 
Cabañas Bravo, M (2013). La crítica ocasión de la II Bienal Hispanoamericana de Arte. Revista de Historiografía (19)

García Canclini, N (1993). El consumo cultural en México. México: Conaculta.

García Canclini, N (2012). Consumidores y ciudadanos. México: Peguin Random House Grupo Editorial México.

Cantón, J. \& Hurtado, D. (2006). Cuba 42 años de Revolución. Cronología histórica 1959 - 1982 Tomo I. La Habana: Ciencias Sociales

Gramatges, H. (1951). Manifiesto. Nuestro Tiempo (1)

Linares, M T. (1954). La tonada campesina y la música cubana. Nuestro Tiempo (17) Martínez, C N. (2019). La Sociedad Cultural Nuestro Tiempo. Impronta de una cruzada por la cultura cubana (1951-1961). (Tesis de Licenciatura) Universidad de Pinar del Río Hermanos Saiz Montes de Oca, Pinar del Río.

Martínez, J A. (1953). Sobre la II Bienal Hispanoamericana de Arte. Diario de la Marina (248)

Mestas, M. d. (2016). Tres entrevistas en torno a Nuestro Tiempo. Obtenido de Librinsula: librinsula.bnjm.cu/secciones/247/entrevistas/247_entrevistas_1.html Otero, R. L. (2002). Sociedad Cultural Nuestro Tiempo. Resistencia y acción. La Habana: Letras Cubanas.

Pogolotti, G. (2010). Política y cultura en Cuba: revisar la historia. Obtenido de La joven Cuba: https://jovencuba.com/2010/07/05/politica-y-cultura-en-cubarevisar-la-historia/

Romero, C. (2003). Vida cultural, prensa periódica y problemática de la etapa. En Colectivo de autores, Historia de la literatura cubana. Tomo II. La literatura entre 1899 y 1958. La República. La Habana: Letras Cubanas.

Saínz, E., \& Hernández, O. (2003). Grupos y publicaciones vanguardistas. En Colectivo de autores, Historia de la literatura cubana. Tomo II. La literatura entre 1899 y 1958. La República. La Habana: Letras Cubanas.

Recibido: 06/06/2020

Evaluado: $08 / 07 / 2020$

Versión Final: 10/08/2020 